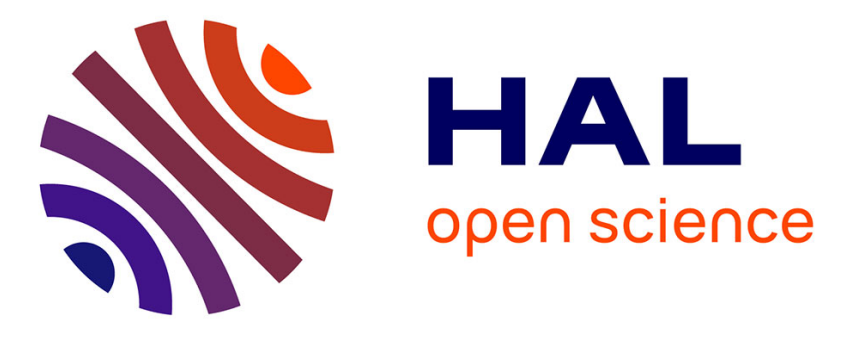

\title{
Progress in Interband Cascade Lasers: from edge emitting lasers to VCSELs
}

Stéphane Calvez, Oleksandr Stepanenko, Daniel A Díaz-Thomas, Thomas

Batte, M. Bahriz, Cyril Paranthoen, Eric Tournié, Christophe Levallois, Alexei Baranov, Guilhem Almuneau, et al.

\section{To cite this version:}

Stéphane Calvez, Oleksandr Stepanenko, Daniel A Díaz-Thomas, Thomas Batte, M. Bahriz, et al.. Progress in Interband Cascade Lasers: from edge emitting lasers to VCSELs. 2020 22nd International Conference on Transparent Optical Networks (ICTON), Jul 2020, Bari, Italy. pp.1-4, 10.1109/ICTON51198.2020.9203274 . hal-02996714

\section{HAL Id: hal-02996714 https://hal.laas.fr/hal-02996714}

Submitted on 9 Nov 2020

HAL is a multi-disciplinary open access archive for the deposit and dissemination of scientific research documents, whether they are published or not. The documents may come from teaching and research institutions in France or abroad, or from public or private research centers.
L'archive ouverte pluridisciplinaire HAL, est destinée au dépôt et à la diffusion de documents scientifiques de niveau recherche, publiés ou non, émanant des établissements d'enseignement et de recherche français ou étrangers, des laboratoires publics ou privés. 


\title{
Progress in Interband Cascade Lasers: from edge emitting lasers
}

\section{to VCSELs}

\author{
Stéphane Calvez ${ }^{1}$, Oleksandr Stepanenko ${ }^{1}$, Daniel Andres Diaz Thomas ${ }^{2}$, Thomas Batte ${ }^{3}$, \\ Michael Bahriz $^{2}$, Cyril Paranthoen ${ }^{3}$, Eric Tournié ${ }^{2}$, Christophe Levallois ${ }^{3}$, Alexei Baranov ${ }^{2}$, \\ Guilhem Almuneau ${ }^{1}$, and Laurent Cerutti ${ }^{2}$ \\ 1: LAAS-CNRS, Université de Toulouse, CNRS, F-31400 Toulouse, France \\ 2: IES, Univ. Montpellier, CNRS, F-34000 Montpellier, France \\ 3: University of Rennes, INSA, CNRS, Institut FOTON, F-35000 Rennes, France \\ Tel: +33 561336 990,Fax: +33 561336 208,e-mail: scalvez@laas.fr
}

\begin{abstract}
Mid-infrared lasers are crucial devices to enable optical spectroscopy in this spectral region of strategic importance for molecular sensing. In this presentation, we will review our recent progress in mid-infrared sources based on interband cascade active regions for operation in the L-band (wavelength of $\sim 3.4 \mu \mathrm{m}$ ) and in particular towards the demonstration of VCSELs, the most promising laser embodiment for energy-efficient portable tunable sources.
\end{abstract}

Keywords: laser, resonant-cavity light-emitting diode, vertical-cavity surface-emitting laser, mid-infrared sources, GaAs, GaSb.

\section{INTRODUCTION}

The water-absorption-free spectral window around $3.4 \mu \mathrm{m}$ is of high interest for spectroscopy applications and, in particular, for environmental monitoring. High-performance semiconductor lasers and light-emitting diodes are considered as key enabling devices for these applications, as well as for free-space communications or light detection and ranging (LIDAR) [1]-[3]. Thanks to the progress made over the last decade [4], emitters relying on interband cascade have become the prominent light sources to generate light in the intermediary mid-infrared Lband $(\sim 3.4 \mu \mathrm{m})$.

In this paper, we summarize the recent studies we have carried out on mid-infrared sources based on interband cascade active regions and more specifically on our progress towards electrically-driven Interband Cascade Vertical-Cavity Surface-Emitting Lasers (IC-VCSELs). For the latter, the selected technological approach seeks 
to extend to longer wavelengths the concept that was successfully demonstrated at $2.3 \mu \mathrm{m}$ [5] which exploits a GaSb-based active mirror completed by a metamorphically-grown AlGaAs/AlOx electro-optical confinement section and a top dielectric mirror.

\section{EDGE-EMITTING LASERS}

As a first step towards the fabrication of hybrid GaAs/GaSb IC-VCSELs, we started our investigations by ensuring that laser operation from large-area edge-emitting lasers could be achieved using the chosen 7-stage quantum-well/injection IC active region whose design is fully described in [6]. Two sets of devices were grown and fabricated. As illustrated in Figure 1, the reference structure layout relied on conventional Te-doped $\mathrm{AlSb} / \mathrm{InAs}$ cladding layers while the second used a metamorphic Te-doped GaAs upper cladding to study the influence of the latter on the device performance.
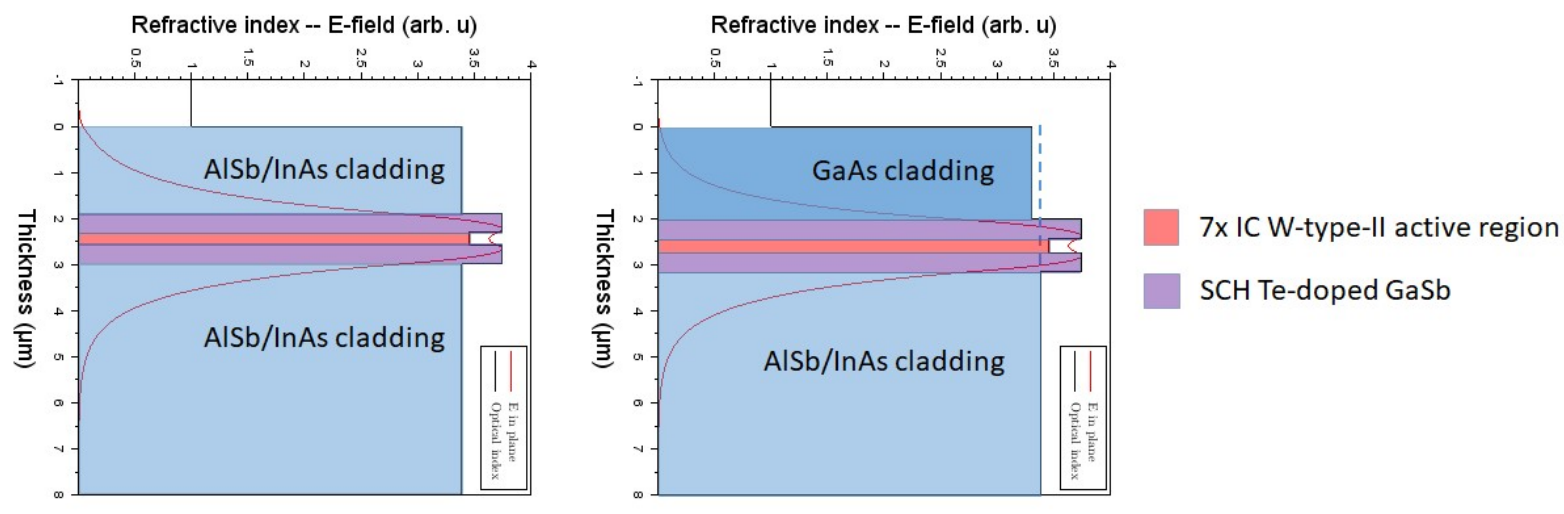

Figure 1. Schematic structural layout of the studied edge-emitting lasers and corresponding E-field profiles.

Episide-up-mounted 4-mm-long broad-area lasers with a stripe width of $100 \mu \mathrm{m}$ were fabricated using the established process reported in [6] with an upper Ti/Au metallic contact and a Pd/AuGeNi back contact. Characterisation under pulsed $(1 \mu \mathrm{s}-1 \mathrm{kHz})$ excitation at room temperature is shown in Figure 2. The reference device exhibits performance on a par with the state-of-the-art [4]. The GaAs-cladded device was also shown to operate successfully but with slightly reduced performance as a consequence of the presence of dislocations and also of a Schottky-barrier at the interface between the GaAs and the Ti-Au contact. In both cases, the lasers were able to operate at mount temperature exceeding $40^{\circ} \mathrm{C}$. 


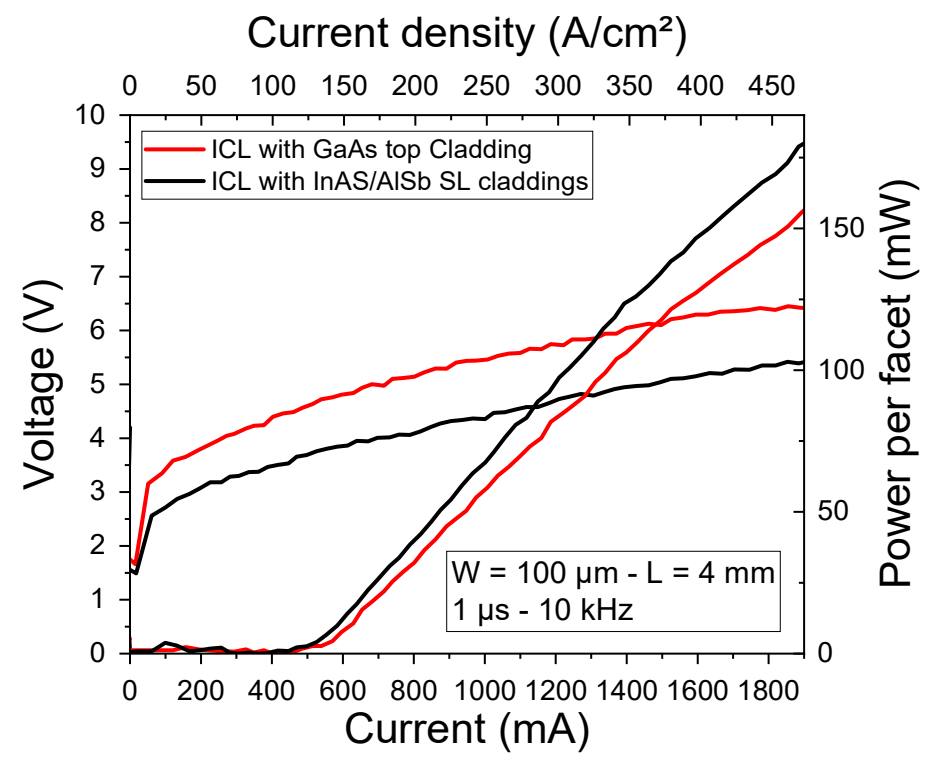

Figure 2. Schematic structural layout of the studied edge-emitting lasers

\section{VERTICAL-CAVITY SURFACE-EMITTING LASERS}

Having established successful active region design and growth parameters, the next step towards the demonstration of IC-VCSELs was to define, fabricate and test vertically-emitting micro-cavity sources.

As mentioned in the introduction, the aim is to extend to the $\sim 3.4-\mu \mathrm{m}$-wavelength band the architecture we demonstrated at short mid-infrared wavelengths [5]. The approach relies on a dielectric-mirror-coated semiconductor section, the latter consisting of a lattice-matched $\mathrm{AlAsSb} / \mathrm{GaSb}$ Distributed Bragg Reflector and a 3- $\lambda$-thick microcavity (see Figure 3). More specifically, the micro-cavity embeds a highly-doped InAsSb bottom contact layer positioned at the first node of optical field, the validated IC-based gain section, and a metamorphic AlGaAs section whose $\mathrm{GaSb} / \mathrm{GaAs}$ interface is also set at a node of the optical field to limit the impact of the dislocation-induced losses. The latter GaAs/AlAs/GaAs stack was chosen to be $5 \lambda / 4$-thick to provide sufficient lateral spreading for the top contact carriers and to introduce, as commonly used in near-infrared $(800-1000 \mathrm{~nm})$ VCSELs, electro-optical confinement upon lateral wet oxidation of the AlAs layer. The considered VCSELs include a 24-pair semiconductor DBR and a 5-pair ZnS/Ge mirror. 


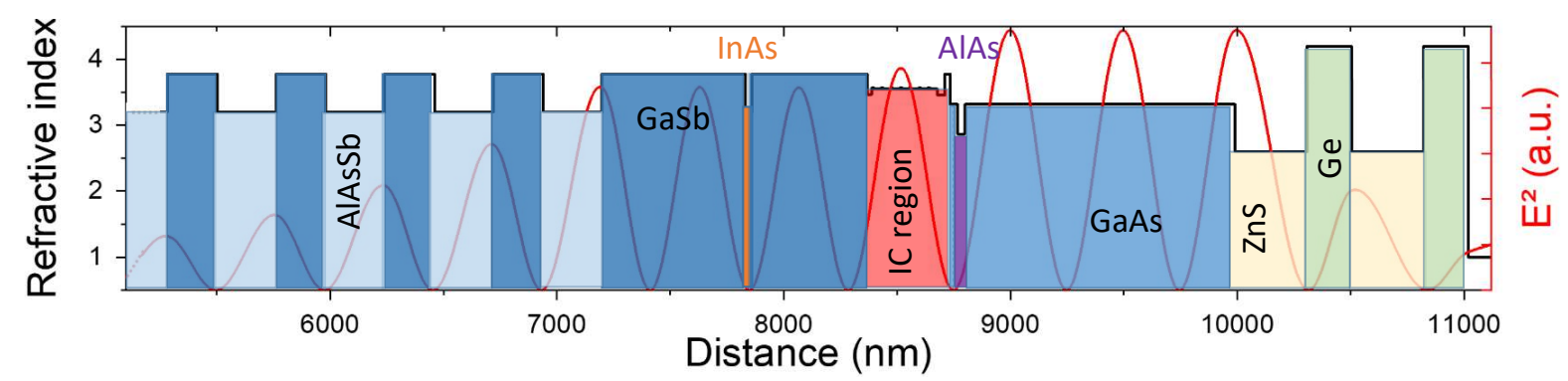

Figure 3. Layout of the micro-cavity part of the RCLED/VCSEL under study

The growth of the semiconductor part was performed on 2-inch (100)-oriented n-type GaSb substrates by molecular beam epitaxy in a RIBER Compact $21 \mathrm{E}$ solid source system equipped with As- and Sb- valved cracker cells. The growth conditions were adjusted throughout the structure to match the design and achieve the best possible (luminescence) performance. The device fabrication will reported elsewhere. It involved the definition of circular mesas by lithography and dry-etching, the oxidation of the AlAs layer to form the lateral apertures, the deposition of metal contacts and SiNx-passivating layers and as well as a selected-area dielectric mirror coating using a lift-off technique. Typical images of representative devices taken at the end of the process are presented in Figure 4. Figure 5 shows the reflectivity and electroluminescent curves measured respectively on the semiconductor part and on the complete VCSELs. These curves suggest successful fabrication of the structures from both optical and electrical stand points.
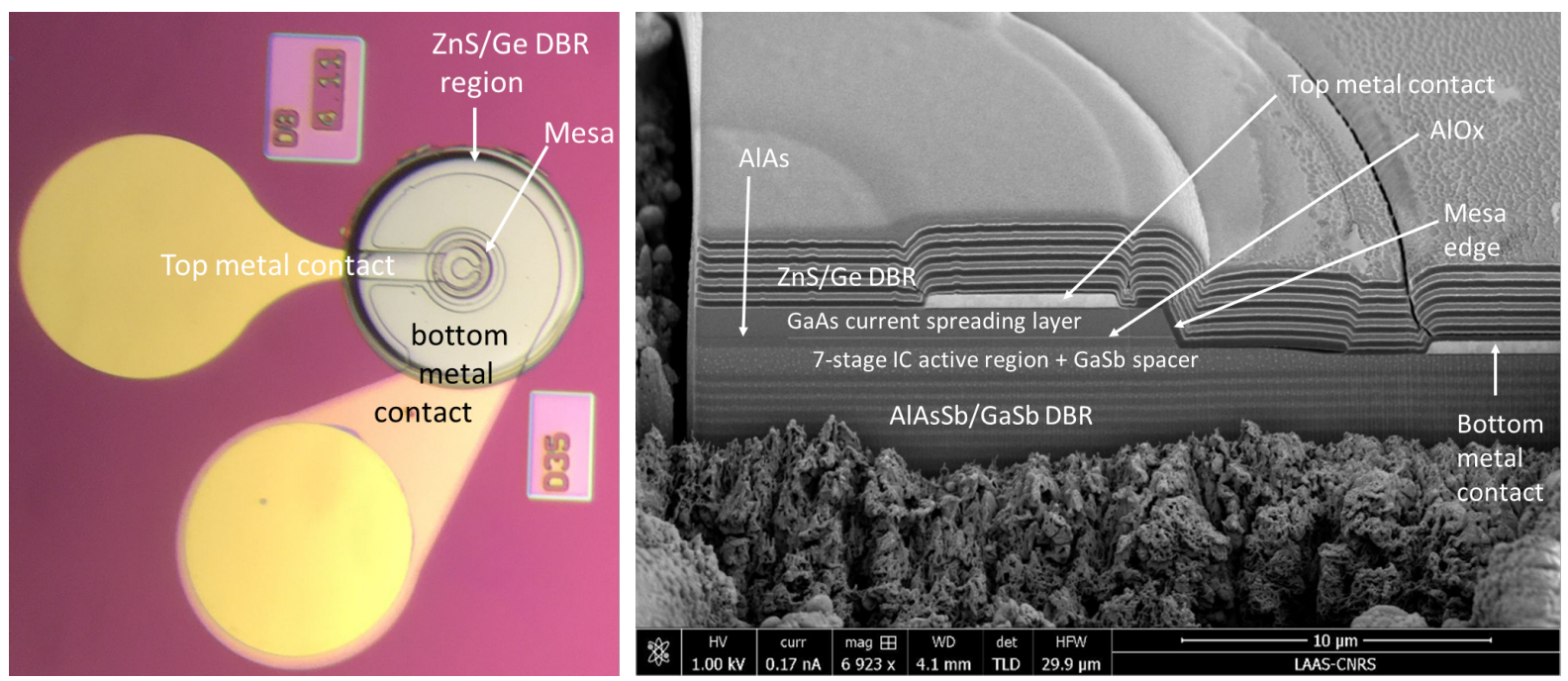

Figure 4. Optical (left) and Scanning Electron Microscope (of a Focussed-ion-beam-cut cross-section) 

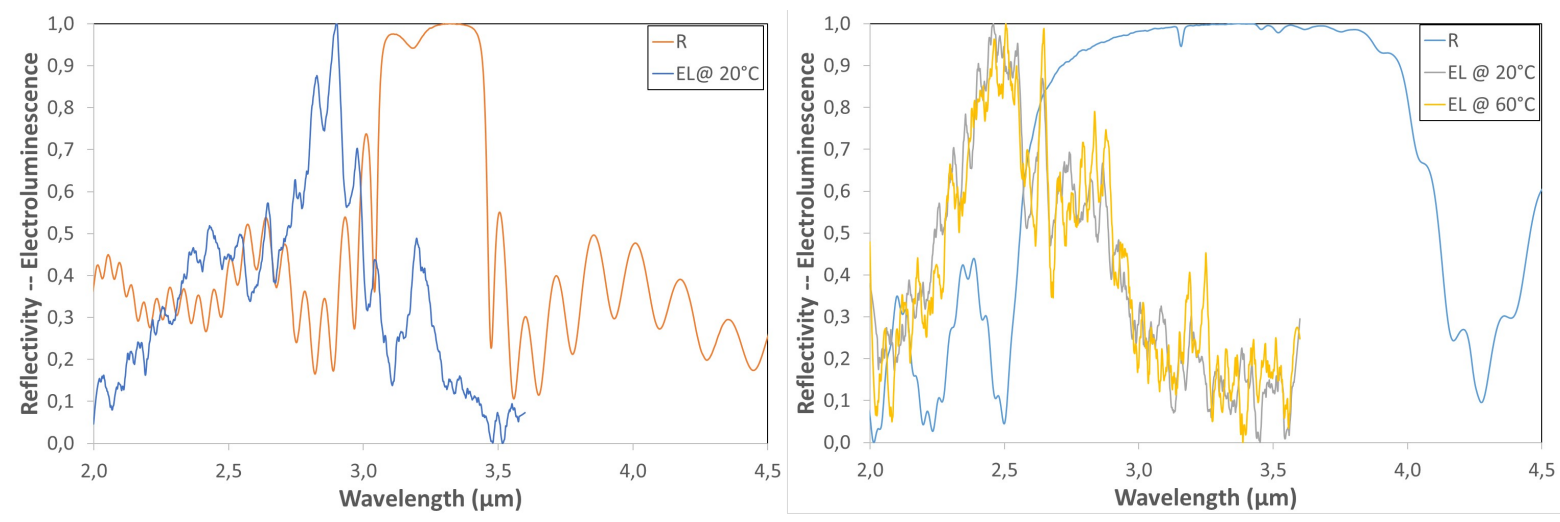

Figure 5. Reflectivity and electroluminescent characteristics

of the VCSEL semiconductor part (left) and complete device (right).

Figure 6 shows the LIV characteristics of $50-\mu \mathrm{m}$-wide-apertured VCSELs for a set of temperatures. Laser operation can not be reached with these devices. Given the above-presented electroluminescent characteristics and the observation that the power increases with temperature, the gain-peak is, as expected, blueshifted compared to the microcavity resonance but this offset turns out to be too large and prevents laser action. Moreover, the turn-on voltage is also observed to be slightly higher than expected, consistent with the behaviour observed for the edge-emitting lasers with AlGaAs metamorphic claddings.

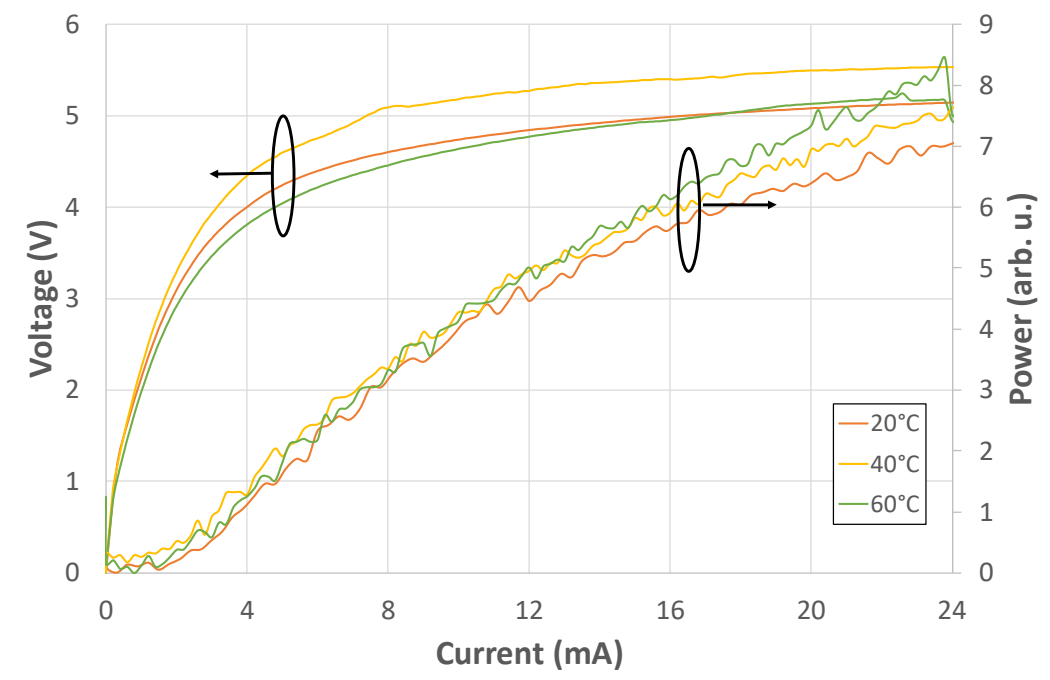

Figure 6. L-I-V characteristics of 50 $\mu$ m-wide-apertured VCSELs as a function of temperature 
At this time, new VCSEL structures with shorter target resonance wavelength and thus more appropriate gainresonance offsets are under process. All the results will be presented at the meeting.

\section{CONCLUSIONS}

In this paper, we have reported the recent progress we have made on various mid-infrared sources based on interband cascade active regions namely edge-emitting lasers and Vertical-Cavity Surface-Emitting Lasers. For the latter two types of devices, the approach exploits a $\mathrm{ZnS} / \mathrm{Ge}$-mirror-coated semiconductor part which includes a GaSb-based active mirror with a metamorphically-grown AlGaAs/AlOx electro-optical confinement top injection section. If successful continuous-wave operation of the EELs was achieved, the current set of VCSELs exhibits a too large gain-to-resonance detuning to reach laser operation. Nevertheless, this work paves the way towards the demonstration of electrically-driven VCSELs operating in the mid-infrared L-band integrating a proper electro-optic confinement scheme contrary to the recently reported devices [7].

\section{ACKNOWLEDGEMENTS}

The authors would like to acknowledge partial financial support from the ANR MIMIC-SEL (ANR-16-CE240011), from the French Program "Investment for the Future" (Equipex EXTRA, ANR-11-EQPX- 0016) and from Renatech, the French network of cleanroom facilities.

\section{REFERENCES}

[1] A. Soibel et al., " Midinfrared Interband Cascade Laser for Free Space Optical Communication », IEEE Photon. Technol. Lett., vol. 22, nº 2, p. 121-123, janv. 2010, doi: 10.1109/LPT.2009.2036449.

[2] M. Jahjah, A. Vicet, et Y. Rouillard, «A QEPAS based methane sensor with a $2.35 \mu \mathrm{m}$ antimonide laser », Appl. Phys. B, vol. 106, no 2, p. 483-489, févr. 2012, doi: 10.1007/s00340-011-4671-4

[3] R. Ghorbani et F. M. Schmidt, «ICL-based TDLAS sensor for real-time breath gas analysis of carbon monoxide isotopes », Opt. Express, vol. 25, n 11, p. 12743, mai 2017, doi: 10.1364/OE.25.012743.

[4] I. Vurgaftman et al., «Interband cascade lasers », J. Phys. D: Appl. Phys., vol. 48, n 12, p. 123001, avr. 2015, doi: 10.1088/0022-3727/48/12/123001.

[5] Y. Laaroussi et al., «Oxide-confined mid-infrared VCSELs », Electronics Letters, vol. 48, $\mathrm{n}^{\circ} 25, \mathrm{p}$. 1616-1618, déc. 2012, doi: 10.1049/el.2012.3572.

[6] D. A. Díaz-Thomas et al., « Interband cascade Lasers with AlGaAsSb cladding layers emitting at $3.3 \mu \mathrm{m} »$, Opt. Express, vol. 27, n 22, p. 31425, oct. 2019, doi: 10.1364/OE.27.031425. 
[7] V. Jayaraman et al., "Tunable room-temperature continuous-wave mid-infrared VCSELs », in VerticalCavity Surface-Emitting Lasers XXIV, San Francisco, United States, févr. 2020, p. 20, doi: $10.1117 / 12.2541514$. 